\title{
Um olhar sobre a reeducação das relações etnicorraciais
}

\author{
Ana Lúcia Silva Souza \\ Universidade Federal da Babia (Salvador, Brasil)
}

\begin{abstract}
RESUMO: O ARTIGO ABORDA AS IMPLICAÇÕES DA SANÇÃO DA LEI 10.639/03 QUE ALTEROU A LEI DE DIRETRIZES E BASES (LDB), TORNANDO OBRIGATÓRIA A INCLUSÃO DA “HISTÓRIA E CULTURA AFRO-BRASILEIRA" NOS SISTEMAS DE ENSINO BRASILEIRO, E INSTITUINDO NO CALENDÁRIO ESCOLAR O DIA 20 DE NOVEMBRO COMO O DIA NACIONAL DA CONSCIÊNCIA NEGRA. ANALISAREMOS COMO, NESTE NOVO CENÁRIO, A ESCOLA - EMBORA NÃO A ÚNICA - SE TORNA A INSTITUIÇÃO CHAVE PERANTE OS AVANÇOS E DESAFIOS DE UMA REESTRUTURAÇÃO CURRICULAR FUNDAMENTAL PARA O EFETIVO RECONHECIMENTO DAS DIVERSIDADES E A PROMOÇÃO DA IGUALDADE RACIAL NO BRASIL.
\end{abstract}

ABSTRACT: THIS ARTICLE DISCUSSES THE IMPLICATIONS OF LAW 10.639/03, WHI$\mathrm{CH}$, BY AMENDING THE OFFICIAL DIRECTIVES FOR EDUCATION IN BRAZIL, MADE THE TEACHING OF AFRO-BRAZILIAN HISTORY AND CULTURE MANDATORY IN THE COUNTRY'S SCHOOL SYSTEM AND DECLARED NOVEMBER 2OTH "NATIONAL BLACK CONSCIOUSNESS DAY". WE SHALL ANALYZE HOW, IN THIS NEW SCENARIO, SCHOOLS (THOUGH BY NO MEANS ALONE) HAVE A KEY ROLE TO PLAY IN REORGANIZING THE CURRICULUM. THIS REORGANIZATION IS CRUCIAL FOR THE RECOGNITION OF BRAZIL'S DIVERSITY AND THE PROMOTION OF RACIAL EQUALITY IN THE COUNTRY.

PALAVRAS-CHAVE: EDUCAÇÃO ETNICORRACIAL, LEI 10.639/03, CURRÍCULO ESCOLAR, CONSCIENTIZAÇÃO.

KEYWORDS: ETHNIC AND RACIAL ISSUES IN EDUCATION, BRAZILIAN LAW 10.639/03, CURRICULUM, CONSCIOUSNESS. 
Eu ouvi falar sobre essa Lei aqui na escola, mas para dizer bem a verdade não sei bem o que ela significa. Mesmo assim me dá a sensação de que vem é mais coisa pra gente fazer na sala de aula. É tanta coisa, tanta novidade que às vezes a gente fica perdida e nem dá tempo de ver os conteúdos. Pergunto eu para que ela pode servir?

Fala hipotética (?) de uma educadora

Lei referida na epígrafe deste texto é a Lei 10.639/03, promulgada em 09 de janeiro de 2003, que alterou a Lei de Diretrizes e Bases da Educação Nacional 9394/96 - LDBEN - nela incluindo o Artigo 26-A e o 79-B, tornando obrigatório o ensino de História e cultura afro-brasileira nos sistemas de ensino público e particular, e instituindo no calendário escolar o 20 de novembro como o "Dia Nacional da Consciência Negra" (BRASIL, 2003). A sanção da Lei 10639/03 mostra-se importante medida de ação afirmativa que, juntamente com a aprovação da Resolução 01/2004, pelo Conselho Nacional de Educação, que estabeleceu as Diretrizes Curriculares Nacionais para a Educação das Relações Étnicorraciais e para o Ensino de História e Cultura Afro-Brasileira e Africana, respondem a um conjunto de reivindicações históricas dos movimentos sociais negros, em meio a um contexto de consolidação de reformas de Estado em curso desde 1995 no Brasil (MONTEIRO, 2010).

Por outro lado, a fala reproduzida na epígrafe é bastante ouvida, e acolhida, em diversos eventos formativos sobre relações raciais - cursos, palestras, seminários - dos quais tenho participado como formadora, palestrante e ouvinte. E é do lugar de formadora que friso a importância de se atentar para indagações dessa ordem, ao menos por duas razões: a primeira, porque a indagação espelha muitas outras vozes sociais que demonstram dúvidas, constrangimentos, inquietações, não raro, medo e até mesmo repulsa quando o foco é a discussão sobre relações raciais na sociedade brasileira; a segunda razão é o fato de a declaração indicar que já não é mais possível fugir a este debate no ambiente escolar.

A fala/epígrafe indica que, bem ou (ainda) mal compreendidos, estes marcos legais, cujo eixo é a referida Lei, têm cumprido o seu papel de intensificador do debate em torno do processo - ainda tímido, com avanços e recuos - de implementação de políticas públicas para a promoção da igualdade racial 
no Brasil. E é com o aval de tais políticas de ações afirmativas que se tem intensificado as demandas para um reordenamento das concepções de ensino, com abordagens a essas disciplinas na escola brasileira. Afinal, entender as transformações e reinvenções das culturas e tradições é a chave para se chegar ao fim do silêncio em torno das diversas facetas do racismo na sociedade brasileira e para fomentar a valorização e o respeito às diferenças.

\section{Mudança curricular, mudança de posturas}

Neste cenário, a necessidade de mudança curricular ganha centralidade, passando o currículo a ser entendido como lugar, espaço, território no qual são incentivados as discussões, o entendimento e as negociações das relações de poder (SILVA, 1999, p. 150). Trata-se então de considerar a reestruturação curricular com vista à introdução de novos conteúdos, mas também, e sobretudo, de fazer emergir problematizações, redirecionamentos conceituais e metodológicos capazes de implicar ações concretas e cotidianas contra o racismo e as discriminações de toda ordem. Conforme explicita o $1^{\circ}$ e $2^{\circ}$ parágrafos do Artigo $2^{\circ}$ das Diretrizes Curriculares Nacionais para a Educação das Relações Étnicorraciais e para o Ensino de História e Cultura Afro-Brasileira e Africana:

Parágrafo $1^{\circ}$ : A educação das relações étnicorraciais tem por objetivo a divulgação e produção de conhecimentos, bem como de atitudes, posturas e valores que eduquem cidadãos quanto à pluralidade étnicorracial, tornando-os capazes de interagir e de negociar objetivos comuns que garantam, a todos, respeito aos direitos legais e valorização de identidade, na busca da consolidação da democracia brasileira.

Parágrafo $2^{\circ}$ : O ensino de História e Cultura Afro-Brasileira e Africana tem por objetivo o reconhecimento e valorização da identidade, história e cultura dos afrobrasileiros, bem como a garantia de reconhecimento e igualdade de valorização das raízes africanas da nação brasileira ao lado das indígenas, européias e asiáticas.

O fato de vivermos ainda numa sociedade caracterizada por desigualdades raciais, além de sociais, conclama a todos, sem distinção, a se aproximarem 
destes urgentes esforços de ações afirmativas, considerando-os uma possibilidade de reflexões intensas e coerentes, num momento democraticamente privilegiado para a revisitação de condutas e a busca de referenciais para a construção da efetiva equidade.

A fala da educadora, na epígrafe, tomada como hipótese de uma ocorrência real - basta uma observação empírica em salas de professores Brasil afora -, revela que apreender o significado dos novos marcos legais requer disposição não apenas no ambiente escolar, mas no âmbito político e social mais abrangente. É preciso disposição, de ordem individual e coletiva, para se romper o opaco véu da ignorância e compreender como foram construídas as concepções rácicas e racistas ao longo da história, e como tais processos colaboram para a sustentação de esquemas interpretativos "que informam e orientam as práticas preconceituosas e discriminatórias, muitas vezes silenciosas, silenciadas e naturalizadas" (SOUZA e CROSSO, 2007). Para um posicionamento estratégico de combate ao racismo há que se admitir e compreender como ele existe e resiste. Assim, ao apresentar o trabalho intitulado Igualdade das relações raciais na escola: possibilidades e desafios para a implementaşão da Lei 10.639/03, Souza e Crosso (2007) enfatizam a necessidade de encarar, de uma vez por todas, com ou sem medo, as diversas facetas das descordialidades brasileiras. Dizem:

problematizar a ideia de um Brasil da democracia racial ou como a democracia racial nos dias de hoje se faz mito e continua a reproduzir e sustentar doutrinas, opiniões e atos racistas, inclusive reconhecendo que o racismo no Brasil é elemento estruturante de nossas relações e continuam hierarquizando as diferenças e inferiorizando um grupo, o negro, em detrimento de outro, o branco (p. 20).

Contudo, registra-se que os últimos anos trouxeram entre outros avanços a qualificação e o aumento do volume das discussões em torno da desconstrução do racismo e a valorização de culturas invisibilizadas, cujas vozes altissonantes dos setores mais engajados da sociedade se fizeram ouvir, inclusive nas instâncias governamentais, afinal falamos de políticas públicas. Mas, as respostas às indagações que, corretamente, continuam firmes na ordem do dia não estão somente no fazer educativo, no chão da escola, mas dependem, em grande parte, de ações conjuntas da sociedade brasileira, no interesse de 
seus cidadãos e, além fronteiras, no interesse da dizimação dessa chaga de difícil, mas não impossível, cicatrização que é o racismo.

A escola, dado à sua legitimidade no que tange ao caráter formativo, é o locus privilegiado para se agenciar as alterações de base dessa realidade. A tarefa é grande e requer aprendizagens que

questionem relações étnicorraciais baseadas em preconceitos que desqualificam os negros e salientam estereótipos depreciativos, palavras, atitudes que, velada ou explicitamente violentas, expressam sentimentos de superioridade em relação aos negros, próprios de uma sociedade hierárquica e desigual (BRASIL, 2005, p. 12).

Na escola tem-se a possibilidade de construir novos percursos, nos quais novas identidades sejam forjadas.

\section{O aprendizado do(a) mestre}

Grande ênfase tem sido dada à formação continuada de professores, com vista a dar suporte às práticas pedagógicas cotidianas. São cursos, palestras, seminários, simpósios, oficinas em diversos âmbitos e formatos, e com abordagens distintas, mas pouca ou quase nada se tem feito em termos de formação inicial. Seriam bem-vindos, por exemplo, conteúdos programáticos trazendo, de forma abrangente, aspectos sócio-históricos da questão racial no Brasil, envolvendo a História da África pré-colonial e da contemporânea para que educadores e educadoras possam concatenar as novas informações com os conteúdos curriculares já sabidos, com foco nas diretrizes curriculares em questão.

Os cursos de formação, capacitação, extensão, enfim, cursos de curta ou média duração, nem sempre são suficientes (apesar dos esforços de todos os envolvidos no processo) para que os participantes adquiram o conhecimento necessário para incluirem, de maneira tranquila, o conteúdo aprendido em seus planos de aula ou projetos didáticos, com organicidade e coerência. Obviamente, a situação atual é um fato dado e a implementação dos novos parâmetros na educação é um work in progress, ou seja, os mestres que já estão na lida cotidiana empreenderão um esforço inicial redobrado de aprendizagem e reprodução 
dessa aprendizagem na reeducação das relações raciais. Acresce a isso a tarefa desses educadores e educadoras, predispostos à mudança, de "conquistar" o apoio pedagógico dentro de suas unidades escolares, onde nem sempre encontram a acolhida necessária para reorganizar, pensar, lapidar seus planos de curso, continuar os debates e repensar o projeto político-pedagógico da escola.

Os participantes das formações, em especial os educadores e educadoras ou já envolvidos com a discussão ou os que estão sensibilizados para tal, tomam a reestruturação curricular como uma necessidade, e buscam a continuidade na organização de grupos de estudos nos quais pesquisam, elaboram, experimentam e realizam diversas ações. Podemos dizer que temos avanços quando ouvimos relatos de eventos centrados na confecção de livros de tecido, de máscaras, de bonecas negras, na mediação de leitura com o uso de recursos diversos tais como vídeos, imagens, os contos e mitos, análise de material midiático. Contudo, um olhar mais atento para muitas dessas ações deixa entrever atividades pontuais, não raramente restritas aos meses de maio e novembro (Abolição e Dia da Consciência Negra, respectivamente), que nos provocam outras reflexões. Quais são os princípios e objetivos educativos que sustentam tais atividades? Em que instâncias são negociadas e explicitadas as intenções políticas de modo que o processo de gestação e desenvolvimento das atividades e projetos sejam oportunidades de aprofundamento do entendimento de aspectos importantes para a reeducação das relações raciais não apenas dentro da sala de aula?

Há avanços, mas há também desafios nesse percurso da reestruturação e prática de um currículo que favoreça a educação para as relações étnicorraciais, uma vez que a mudança de postura, e consequentemente, a mudança de ações relativas à questão racial, que tem um importante significado para os grupos de educadores, não corresponde necessariamente à mudança nas escolas, nos projetos político-pedagógicos e na organização dos currículos. Sem a institucionalização do trabalho, a materialização do intenso processo de formação continuada, o processo tende a acomodar-se no rol das atividades isoladas e individuais que pouco alteram o intrincado jogo de poder no qual estamos todos envolvidos, querendo ou não, assumindo ou não, independentemente do pertencimento étnicorracial.

Ao lado dos avanços estão os desafios e as possibilidades, o que requer pensar quais, porque e como determinados princípios e questões organizarão 
o currículo das unidades escolares, sustentando um projeto político-pedagógico que traga á tona as questões referentes à população negra e indígena.

A inserção de ações políticas e pedagógicas voltadas para as relações raciais, da cultura afro-brasileira e africanas, não se esgota com a abordagem dos temas afins. Antes disso, diz respeito ao incremento da formação inicial e programas de formação continuada e também ao fazer pedagógico cotidiano que contemple esta questão, juntamente com outras relações de gênero e sexualidade, entre outras diferenças certamente presentes nas escolas.

Para além da movimentação de conteúdos, é necessário considerar a inserção das Diretriz̧es no projeto pedagógico de cada escola como um conjunto de valores, e que estas diretrizes interfiram na gestão da escola e não apenas da sala de aula, cotidianamente. Os projetos - feitos e refeitos permanentemente, serão uma das formas privilegiadas de trabalho, dando corpo a um processo de busca de conhecimentos. Para além dos dispositivos legais, trata-se de inserir-se num processo de reeducação: conhecer, entender, esmiuçar, rever, reconstruir as ideias, noções e práticas que até então ampararam as desigualdades étnicorraciais que se fazem presentes em todos os níveis de ensino. Tanto melhor se envolver gestores educacionais, coordenadores, orientadores, professores, alunos, pais/responsáveis, demais profissionais que atuam na escola.

É sobretudo nesse sentido que reflito sobre o amadurecimento que pode nos permitir indagações, buscas, reflexões, e não nos fará desistir, ao menos tão facilmente, diante dos desafios e das possibilidades.

\section{Referências bibliográficas}

BRASIL. MINISTÉRIO DA EDUCAÇÃO. Lei 10.639/03, de 9 de janeiro de 2003. Altera a Lei 9.394, de 20 de dezembro de 1996. D. O. U. 10 de janeiro de 2003. BRASIL, MINISTÉRIO DA EDUCAÇÃO. Diretriz̨es Curriculares Nacionais e para a Educação das Relações étnico-Raciais e para o Ensino de História e Cultura Afro-Brasileira e Africana. (CNE/CP 003/2004, de 10 de março de 2004). Brasília: MEC/ SECAD, 2005.

BRASIL, MINISTÉRIO DA EDUCAÇÃO. Orientações a Ações Para a Educação das Relações Étnico-Raciais. Brasília: MEC/ SECAD, 2006.

MONTEIRO, R.B. A educação para as relações étnicorraciais em um curso de pedagogia: estudo de caso sobre a implementação da resolução CNE/CP/01/2004. Tese de Doutorado. São Carlos: UFSCar, São Carlos, 2010. 
SILVA. T.T. da. Documentos de Identidade: uma introdução às teorias do currículo. Belo Horizonte: Autêntica, 1999.

SOUZA, A. L e CROSSO, C. Igualdade das relacões raciais na escola: possibilidades e desafios para a implementação da Lei 10.639/03. São Paulo: Peirópolis, Ação Educativa, Ceafro e Ceert, 2007.

Recebido em 10 de julho e aprovado em 15 de setembro de 2010. 